\title{
Correction to: Detecting eukaryotic microbiota with single-cell sensitivity in human tissue
}

Susanne Lager ${ }^{1,2}$, Marcus C. de Goffau ${ }^{3}$, Ulla Sovio ${ }^{1,2}$, Sharon J. Peacock ${ }^{3,4,5}$, Julian Parkhill ${ }^{3}$,

D. Stephen Charnock-Jones ${ }^{1,2}$ and Gordon C. S. Smith ${ }^{1,2^{*}}$

\section{Correction}

The author reported an error in an equation in the article [1].

The incorrect formula shown is the following:

$$
\text { Correction factor }=\frac{1+(99.9-H u m a n(\%))}{\text { Human }(\%)}
$$

The correct formula should be:

$$
\text { Correction factor }=1+\frac{99.9-\operatorname{Human}(\%)}{\operatorname{Human}(\%)}
$$

\section{Author details}

'Department of Obstetrics and Gynaecology, University of Cambridge, National Institute for Health Research Cambridge Biomedical Research Centre, Cambridge, UK. ${ }^{2}$ Centre for Trophoblast Research (CTR), Department of Physiology, Development and Neuroscience, University of Cambridge, Cambridge, UK. ${ }^{3}$ Wellcome Trust Sanger Institute, Cambridge, UK.

${ }^{4}$ Department of Medicine, University of Cambridge, Cambridge, UK. ${ }^{5}$ London School of Hygiene and Tropical Medicine, London, UK.

Published online: 20 October 2018

\section{Reference}

1. Lager S, de Goffau MC, Sovio U, Peacock SJ, Parkhill J, Stephen Charnock-

Jones D, Smith GCS. Detecting eukaryotic microbiota with single-cell sensitivity in human tissue. Microbiome. 2018;6:151.

\footnotetext{
*Correspondence: gcss2@cam.ac.uk

'Department of Obstetrics and Gynaecology, University of Cambridge,

National Institute for Health Research Cambridge Biomedical Research

Centre, Cambridge, UK

${ }^{2}$ Centre for Trophoblast Research (CTR), Department of Physiology,

Development and Neuroscience, University of Cambridge, Cambridge, UK
} 